\title{
A Randomized, Prospective, Double-Blind, Placebo-Controlled Evaluation of the Effect of Sedation on Diagnostic Validity of Cervical Facet Joint Pain
}

\author{
Laxmaiah Manchikanti, MD, Vidyasagar Pampati, MSc, Kim S. Damron, RN, Carla D. McManus, RN, BSN,
} Sheila D. Jackson, RN, Renee C. Barnhill, RN, and Jennifer C. Martin, RN

Background: Based on responses to controlled diagnostic blocks of cervical facet joints, the prevalence of cervical facet joint pain in chronic neck pain has been shown to range from $54 \%$ to $67 \%$, with false-positive results of $27 \%$ to $63 \%$ with a single diagnostic block. Other confounding factors claimed to influence the diagnostic validity of cervical facet joint blocks include administration of anxiolytics and narcotics prior to or during the procedure.

Objective: To evaluate the effect of midazolam and fentanyl on the validity of diagnosis of cervical facet joint pain.

Study Design: Randomized, prospective, double-blind, placebo-controlled evaluation.

Methods: The study was undertaken in an interventional pain management practice.
The design consisted of a placebo group receiving sodium chloride solution and two experimental groups receiving either midazolam or fentanyl. The patients included in the study were treated in the past and were presenting for repeat treatment after a significant period of symptom relief.

Outcome Measures: Outcomes were assessed at baseline and after the administration of 1 of the 3 solutions (Group I, sodium chloride solution; Group II, midazolam; or Group III, fentanyl). Outcome measures included numeric pain scale, proportion of pain relief, and ability to perform prior painful movements.

Results: Pain relief of $\geq 80 \%$ was noted in $5 \%$ of the patients in Group I, $8 \%$ in Group II, and $8 \%$ in Group III. However, $\geq 50 \%$ relief was noted in $8 \%$ of the patients in Group I,
$13 \%$ in Group II, and $27 \%$ in Group III. Overall, $8 \%$ of the patients in Group I, $13 \%$ in Group II, and $27 \%$ in Group III were able to perform movements which were painful prior to injection.

Conclusion: The administration of sedation with midazolam or fentanyl is a confounding factor in the diagnosis of cervical facet joint pain in patients with chronic neck pain. However, if $\geq 80 \%$ pain relief with ability to perform prior painful movements is used as the standard for evaluating the effect of controlled local anesthetic blocks, the diagnostic validity of cervical facet joint nerve blocks may be preserved.

Keywords: Chronic neck pain, cervical facet joint pain, controlled comparative local anesthetic blocks, false-positives, confounding factors, analgesia
Pain emanating from the cervical spine constitutes one of the most common pain problems, with lifetime prevalence reports of $65 \%$ to $80 \%$ (1-5). While most neck pain resolves within a short period of time, chronicity of neck pain has been demonstrated in $26 \%$ to $44 \%$ of patients after an initial episode of neck pain or whiplash (6-8). Various structures in the cervical spine, such as facet joints, intervertebral discs, dorsal root ganglia, muscles, and ligaments, are capable of causing neck pain, shoulder pain, upper extremity pain, and headaches (9-12). Facet joints

From Pain Management Center of Paducah, Paducah, kentucky. Address Correspondence: Laxmaiah Manchikanti, MD, 2831 Lone Oak Road, Paducah, Kentucky 42003

E-mail: drm@apex.net

Disclaimer: There was no external funding in preparation of this manuscript.

Funding: Facilities and personnel were provided by Ambulatory Surgery Center and Pain Management Center of Paducah, Paducah, KY 42003.

Conflict of Interest: None

Acknowledgement: Manuscript received on 3/6/04. Revision submitted on 4/4/04. Accepted for publication on $4 / 11 / 04$. have been increasingly recognized as a significant source of neck pain, shoulder pain, upper extremity pain, and cervicogenic headache (10-15). Based on the response to controlled diagnostic blocks of cervical facet joints, in accordance with the criteria established by the International Association for the Study of Pain (16), the prevalence of cervical facet joint pain has been shown to range from $54 \%$ to $67 \%$ in patients with chronic neck pain (17-23).

The evidence for cervical facet joints being a source of neck pain is compelling. Nerve supply to these joints is abundant from the medial branches of the cervical dorsal rami (23-26). Studies of healthy volunteers have shown that distention of these joints with contrast medium provokes neck pain and referred pain (11). Referral patterns have been described by multiple authors $(9,13,14)$. Various studies have shown that neck pain can be relieved by anesthetizing the cervical facet joints by blocking them with intraarticular injections or medial branch blocks (17-24, 27-29); controlled local anesthetic blocks have demonstrated the significant prevalence of cervical facet joint pain (17-21); and local anesthetic blockade or medial branch neurotomy of the cervical facet joints has been shown to provide therapeutic relief (2831 ). Yet, there are no neurophysiologic findings, radiologic findings, physical findings, historical or clinical features that are either clearly indicative or diagnostic of cervical facet joint pain (15, $22,23)$.

Controlled diagnostic blocks with two separate local anesthetics or placebo-controlled blocks are the only means of confirming the diagnosis of facet joint pain in the neck. However, a significant proportion of patients $(27 \%$ to $63 \%$ ) may present with false-positive results (19-21, 32). Even though face validity and construct validity of facet joint blocks has been well established $(24,33,34)$, multiple other confounding factors may affect the diagnostic validity of cervical facet joint blocks. These factors include psychological and 
behavioral status, as well as administration of anxiolytics, narcotics, and other agents. These factors have been extensively discussed with provocative discography $(15,35-38)$. A lack of influence of psychological factors on the validity of comparative controlled diagnostic local anesthetic blocks of facet joints in the low back has been demonstrated (39).

However, the effects of anxiolytics and narcotics on the validity of diagnosis of cervical facet joint pain by means of controlled comparative local anesthetic blocks have not been studied. Anxiolytics, narcotics, and other sedative agents, frequently chosen to provide conscious sedation, promote patient relaxation, prevent movement during the procedure, and promote the acceptance of interventional techniques, may influence the subjective reporting of pain following cervical facet joint injections. Multiple drugs utilized for this purpose include benzodiazepines (including diazepam and midazolam), fentanyl and alfentanil, along with a multitude of other medications including meperidine, morphine, propofol, etc. Midazolam and fentanyl are the most frequently used intervenous drugs for intraoperative sedation and analgesia due to the expected short duration of action combined with rapid onset of action, and high clearance.

This evaluation was conducted to demonstrate the effect of midazolam and fentanyl on the validity of diagnosis of cervical facet joint pain. Patients who were proven to have cervical facet joint pain, demonstrated by fluoroscopically directed controlled comparative local anesthetic blocks and therapeutic measures involving medial branch blocks with good response, but returning for a repeat treatment after a significant period of symptom relief, were included to evaluate the effect of the commonly used drugs midazolam and fentanyl, and compared to placebo injections.

\section{Methods}

The study was undertaken in an interventional pain management practice (a specialty referral center) in a private practice setting. The protocol was approved by the Institutional Review Board. The design consisted of a control group
(Group I) receiving sodium chloride solution, Group II receiving midazolam, and Group III receiving fentanyl.

\section{Informed Consent}

All patients were provided with the approved protocol and informed consent document approved by the Institutional Review Board for this study. The informed consent document described the details of the trial.

\section{Inclusion and Exclusion Criteria}

All the patients who participated of in this study were identified from the existing patients of the interventional pain management practice. All the patients had a proven diagnosis of cervical facet joint pain by controlled comparative local anesthetic blocks, as well as therapeutic medial branch blocks.

\section{Inclusion Criteria}

Patients between 18 and 90 years of age, with a history of chronic, function limiting, neck pain of at least 1 year duration, with confirmed evidence of facet joint pain by controlled comparative local anesthetic blocks and therapeutic medial branch blocks, having demonstrated the ability to understand the investigation, and/or co-operate with the investigational procedures, and with a willingness to participate in the clinical trial were included. All the patients included in the study were treated in the past and were presenting for repeat treatment after a significant period of symptom relief.

\section{Exclusion Criteria}

Patients without confirmed cervical facet joint pain, uncontrolled major depression or other psychiatric disorders, pregnant or lactating women, patients with multiple complaints involving other problems which have overlapping pain complaints, inability to achieve appropriate positioning and inability to understand informed consent and protocol, history of adverse reaction to either midazolam or fentanyl, or unwillingness to participate in the study were excluded

\section{Evaluation}

Evaluation consisted of collection of demographic data, routine physical and medical evaluation, data as to the confirmation of cervical facet joint pain by controlled comparative local anesthetic blocks and response to therapeutic medial branch blocks, with significant symptom relief and necessity for repeat treatment, pain assessment by numeric pain scale, and identification of painful movements.

\section{Study Design and Investigation}

All patients in the three groups were provided identical preparation, along with administration of identical volumes of drugs in unlabeled syringes. The study was performed in the holding area by registered nurses experienced with evaluation, administration of sedatives, narcotics, and monitoring.

Patients in all three groups were brought to the holding area of the surgery center. They were assigned a number. The allocation was based upon a computer generated randomization scheme with 5 of 15 patients to each group. Prior to the administration of the solutions, patients were asked to rate their pain on a numeric pain rating scale of 0 to 10 , with 0 being no pain and 10 being the worst possible pain such as pain of pregnancy and delivery or a kidney stone in women, or a kidney stone in men. The painful movements were also identified.

All patients, based on the randomization, received 1 of the 3 solutions in incremental doses of $1 \mathrm{~mL}$ with a maximum of $5 \mathrm{~mL}$ of $\mathrm{NaCl}$ in Group I, $1 \mathrm{mg}$ of midazolam per $\mathrm{mL}$ ( $5 \mathrm{mg}$ per $5 \mathrm{~mL}$ ) in Group II, or $50 \mathrm{mcg}$ of fentanyl per $\mathrm{mL}$ (250 mg or mcg per $5 \mathrm{~mL}$ ) in Group III. Patient and investigator were blinded to the randomized allocation, as well as solution administered. The solutions were administered slowly based on patient's response with relaxation and/or feeling of drowsiness or until the entire syringe of $5 \mathrm{~mL}$ was administered. Once the patients expressed either drowsiness or relaxation or the maximum dose was administered, assessment of pain on a numeric pain scale and ability to perform painful movements were reassessed. All the results were documented.

After completion of the evaluation, unblinding was carried out and the amount of sedation administered in Group II and III were noted on the record.

\section{Outcomes Assessment}

Outcomes were assessed at baseline and after the administration of 


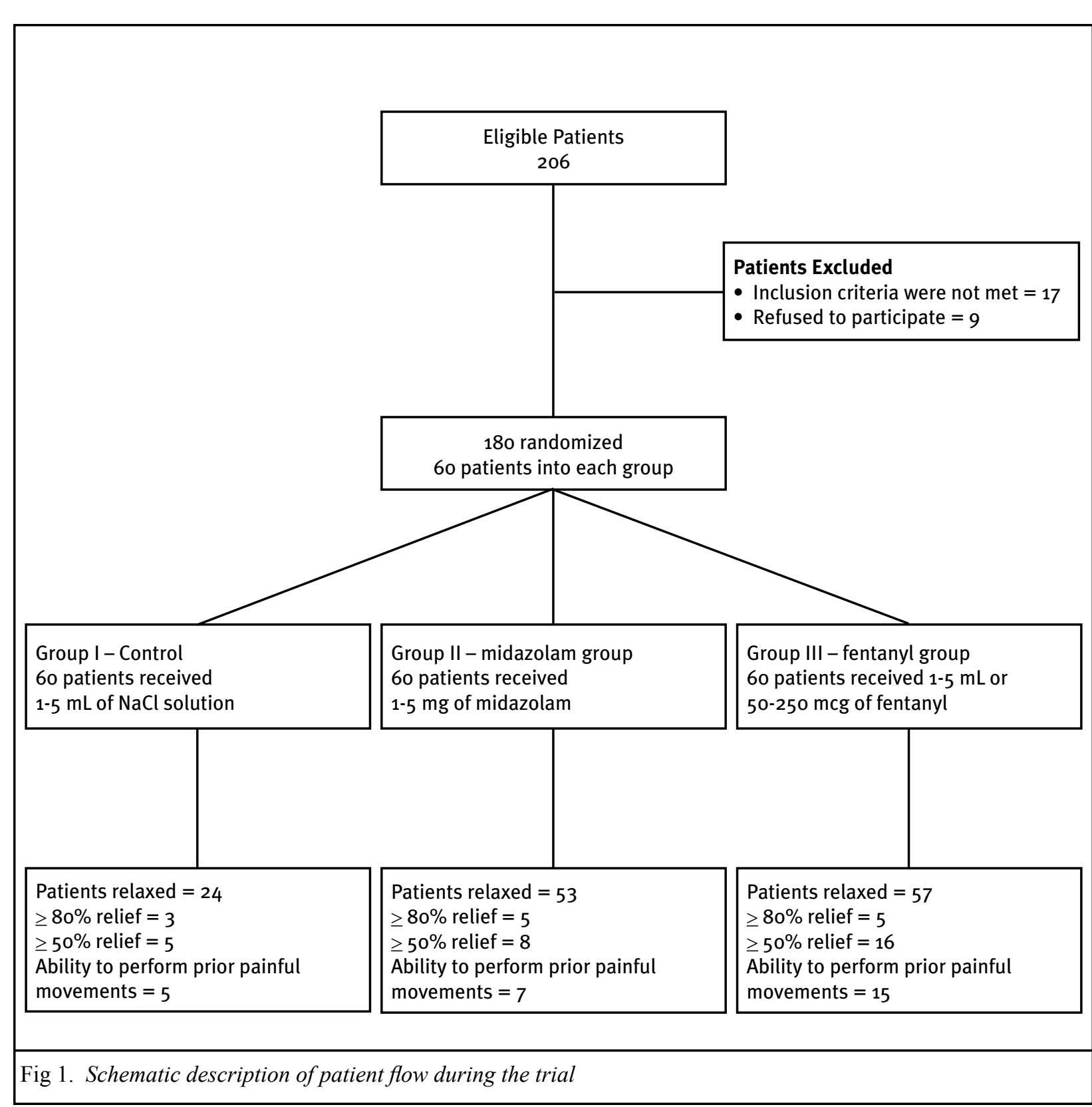

the solution. These included numeric pain scale, proportion of pain relief, and ability to perform prior painful movements.

\section{Statistical Methods}

Data were recorded in a database using Microsoft ${ }^{\circledR}$ Access ${ }^{\circledR}$ 97. The SPSS version 9.0 software was used to generate descriptive tables. Differences in proportions were tested using chi-squared test. Fisher's exact test was used wherever the expected value was less than 5 . Student's t-test was used to test mean significant difference between groups. A paired t-test was used to compare pre- and post-intervention results for individual patients. Results were considered statistically significant if the $P$ value was less than 0.05 . Confidence intervals (95\% CI) and levels ( $95 \%$ CL) were calculated for proportions and means.

\section{RESULTS}

The study was performed over a period of three months extending from February through April of 2004. Patient flow is depicted in Figure 1. From a sample of 586 patients, 180 were randomized with 60 patients into each group.

\section{Demographic Characteristics}

Table 1 illustrates the demographic characteristics of patients. No significant differences were noted with regards to gender, age, height, weight, and post surgery status.

\section{Study Characteristics}

Table 2 illustrates characteristics of administration of drugs and their effect. Time required for relaxation was significantly less in Group III compared to Group I. There were significant differences noted among the groups with amount of solution administered. Pa- 
Table 1. Demographic characteristics

\begin{tabular}{|c|c|c|c|c|}
\hline & & $\begin{array}{l}\text { Group I } \\
\text { Control }\end{array}$ & $\begin{array}{c}\text { Group II } \\
\text { Midazolam }\end{array}$ & $\begin{array}{l}\text { Group III } \\
\text { Fentanyl }\end{array}$ \\
\hline \multirow{2}{*}{ Gender } & Male & $40 \%(24)$ & $30 \%(18)$ & $35 \%(21)$ \\
\hline & Female & $60 \%(36)$ & $70 \%(42)$ & $65 \%(39)$ \\
\hline \multirow{2}{*}{ Age (yrs) } & Range & $28-83$ & $25-79$ & $21-72$ \\
\hline & Mean \pm SD & $48 \pm 11.1$ & $49 \pm 11.5$ & $48 \pm 11.9$ \\
\hline Height (inches) & Mean \pm SD & $67 \pm 4.4$ & $66 \pm 4.2$ & $67 \pm 4.3$ \\
\hline Weight (lbs) & Mean \pm SD & $190 \pm 52.1$ & $176 \pm 45.7$ & $177 \pm 47.0$ \\
\hline \multicolumn{2}{|c|}{ Post Spinal Surgery } & $15 \%(9)$ & $20 \%(12)$ & $12 \%(7)$ \\
\hline
\end{tabular}

tients in Group II and Group III required ences noted between Group II and Group lower dosages $(3.5 \pm 1.2 \mathrm{~mL}, 3.2 \pm 1.0 \mathrm{~mL} \quad$ III.

vs. $4.5 \pm 1.0 \mathrm{~mL}$ ) compared to Group I to achieve satisfactory effect.

Relaxation status also varied in all three groups. Groups II $(88 \%)$ and III $(95 \%)$ had a greater proportion of patients who were relaxed than Group I (40\%). There were no significant differ-

\section{Pain Relief}

Table 3 illustrates characteristics of various pain measurements prior to and after the administration of appropriate drugs or sodium chloride solution. Baseline pain scales were similar in all three

Table 2. Characteristics of administration of drugs and their effect

\begin{tabular}{|c|c|c|c|c|c|}
\hline & & $\begin{array}{l}\text { Group I } \\
\text { Control }\end{array}$ & $\begin{array}{c}\text { Group II } \\
\text { Midazolam }\end{array}$ & $\begin{array}{l}\text { Group III } \\
\text { Fentanyl }\end{array}$ & $P$ Value \\
\hline \multirow{2}{*}{$\begin{array}{l}\text { Time required } \\
\text { for relaxation } \\
\text { (in minutes) }\end{array}$} & Mean \pm SD & $9.6 \pm 3.2$ & $8.9 \pm 2.8$ & $8.3^{\star} \pm 2.7$ & 0.043 \\
\hline & Range & $5-20$ & $3-13$ & $4-13$ & \\
\hline \multirow{6}{*}{$\begin{array}{l}\text { Amount of } \\
\text { solution or } \\
\text { drug dosage } \\
\text { (in } \mathrm{ml} \text { ) }\end{array}$} & $1 \mathrm{ml}$ & $1 \%(1)$ & $2 \%(1)$ & $0 \%$ & \multirow{5}{*}{0.000} \\
\hline & $2 \mathrm{ml}$ & $7 \%(4)$ & $28 \%(17)$ & $28 \%(17)$ & \\
\hline & $3 \mathrm{ml}$ & $7 \%(4)$ & $23 \%(14)$ & $44 \%(26)$ & \\
\hline & $4 \mathrm{ml}$ & $13 \%(8)$ & $17 \%(10)$ & $13 \%(8)$ & \\
\hline & $5 \mathrm{ml}$ & $72 \%(43)$ & $30 \%(18)$ & $15 \%(9)$ & \\
\hline & Mean \pm SD & $4 \cdot 5 \pm 1.0$ & $3.5 \pm 1.2$ & $3.2 \pm 1.0$ & 0.062 \\
\hline \multicolumn{2}{|l|}{ Relaxed Status } & $40 \%(24)$ & $88 \% \star(53)$ & $95 \% *(57)$ & 0.000 \\
\hline \multicolumn{2}{|c|}{$95 \%$ Confidence Interval } & $28 \%-53 \%$ & $80 \%-96 \%$ & $89 \%-100 \%$ & \\
\hline
\end{tabular}

() Number of patients

* Indicates significant difference with Group I

Table 3. Comparison of numeric pain scales

\begin{tabular}{|c|c|c|c|c|c|}
\hline & & $\begin{array}{l}\text { Group I } \\
\text { Control }\end{array}$ & $\begin{array}{c}\text { Group II } \\
\text { Midazolam }\end{array}$ & $\begin{array}{l}\text { Group III } \\
\text { Fentanyl }\end{array}$ & $P$ Value \\
\hline Baseline pain scale & Mean \pm SD & $7 \cdot 3 \pm 1.6$ & $7.5 \pm 2.0$ & $7.6 \pm 1.8$ & 0.603 \\
\hline Post-study follow-up & Mean \pm SD & $6.1 \pm 2.0$ & $5.9 \pm 2.8$ & $5 \cdot 3 \pm 2.8$ & 0.227 \\
\hline Change on pain scale & Mean \pm SD & $1.1 \pm 1.8$ & $1.6 \pm 1.9$ & $2.2^{\star} \pm 2.1$ & 0.008 \\
\hline \multicolumn{2}{|l|}{$95 \%$ Confidence Level } & $0.67,1.60$ & $1.11,2.09$ & $1.7,2.77$ & - \\
\hline \multicolumn{2}{|l|}{$\geq 80 \%$ relief } & $5 \%(3)$ & $8 \%(5)$ & $8 \%(5)$ & 0.718 \\
\hline \multicolumn{2}{|l|}{$\geq \mathbf{5 0} \%$ relief } & $8 \%(5)$ & $13 \%(8)$ & $27 \% *(16)$ & 0.019 \\
\hline \multicolumn{2}{|l|}{$95 \%$ Confidence Interval } & $1 \%-15 \%$ & $5 \%-22 \%$ & $15 \%-38 \%$ & - \\
\hline Proportion of relief or (\%) & Mean \pm SD & $14.5 \pm 24.2$ & $23.0 \pm 27.9$ & $32.0^{\star} \pm 30.1$ & 0.003 \\
\hline \multicolumn{2}{|l|}{ 95\% Confidence Level } & $8.3,20.8$ & $15.8,30.2$ & $24.0,40.0$ & - \\
\hline
\end{tabular}

groups. Post-study follow-up pain scales showed no significant differences among the groups. However, changes on pain scale were significantly higher in Group III compared to Group I, whereas there were no changes noted between Group I and II, or Group II and III. There were no significant differences noted among groups with $\geq 80 \%$ relief, whereas, a greater proportion of patients in Group III presented with $\geq 50 \%$ relief compared to Group I with no significant differences noted between Group I and II, or Group II and III.

Table 4 illustrates the proportion of pain relief in all 3 groups based on the amount of solution injected, with ability to perform movements which were painful prior to injection. Proportion of relief was seen in a significantly greater proportion of patients in Group III compared to Group I with no significant differences noted between Groups I and II, and Groups II and III.

Figures 2 and 3 illustrate the proportion of patients with pain relief and ability to perform baseline painful movements in post-study follow-up period in each group.

\section{Correlation of Various Painful Characteristics}

Table 5 illustrates the ability to perform movements painful prior to injection of solution. There was a significant correlation between $\geq 80 \%$ or $\geq 50 \%$ pain relief, relaxation, and ability to perform painful movements. Most patients with the ability to perform painful movements were relaxed and also had experienced pain relief of $\geq 50 \%$ in all three groups.

* Indicates significant difference with Group I 
Table 4. Proportion of pain relief and ability to perform movements painful prior to injection of solution

\begin{tabular}{|c|c|c|c|c|c|c|}
\hline \multirow[b]{2}{*}{ Percent Relief } & \multicolumn{2}{|c|}{$\begin{array}{l}\text { Group I } \\
\text { Control }\end{array}$} & \multicolumn{2}{|c|}{$\begin{array}{c}\text { Group II } \\
\text { Midazolam }\end{array}$} & \multicolumn{2}{|c|}{$\begin{array}{l}\text { Group III } \\
\text { Fentanyl }\end{array}$} \\
\hline & $\begin{array}{c}\text { Number of } \\
\text { patients }\end{array}$ & \begin{tabular}{|} 
Ability to perform \\
previously \\
painful \\
movements \\
\end{tabular} & $\begin{array}{c}\text { Number of } \\
\text { patients }\end{array}$ & $\begin{array}{c}\text { Ability to perform } \\
\text { previously } \\
\text { painful } \\
\text { movements }\end{array}$ & $\begin{array}{l}\text { Number of } \\
\text { patients }\end{array}$ & $\begin{array}{c}\text { Ability to perform } \\
\text { previously } \\
\text { painful } \\
\text { movements } \\
\end{array}$ \\
\hline $100 \%$ & 2 & 1 & 5 & 5 & 5 & 5 \\
\hline $90 \%$ & 0 & 0 & 0 & 0 & 0 & 0 \\
\hline $80 \%$ & 1 & 1 & 0 & 0 & 0 & 0 \\
\hline $70 \%$ & 0 & 0 & 0 & 0 & 6 & 6 \\
\hline $60 \%$ & 0 & 0 & 0 & 0 & 2 & 1 \\
\hline $50 \%$ & 2 & 2 & 3 & 2 & 3 & 3 \\
\hline$<\mathbf{5 0} \%$ & 55 & 1 & 52 & 0 & 44 & 0 \\
\hline Total & 60 & 5 & 60 & 7 & 60 & 15 \\
\hline
\end{tabular}

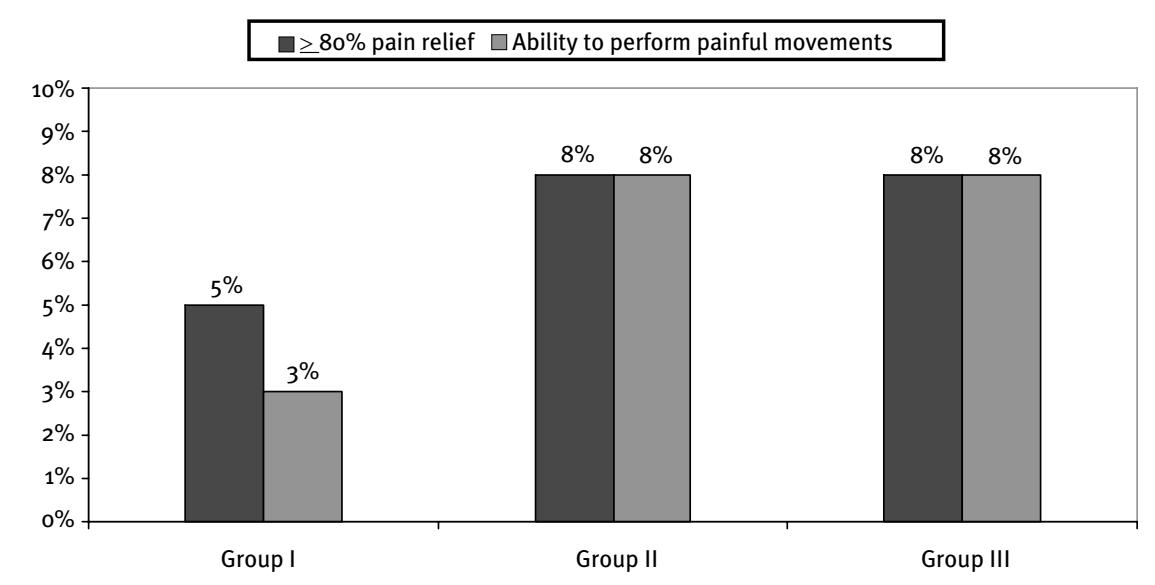

Fig 2. Illustration of $\geq 80 \%$ pain relief and ability to perform baseline painful movements in post-study follow-up period in each group

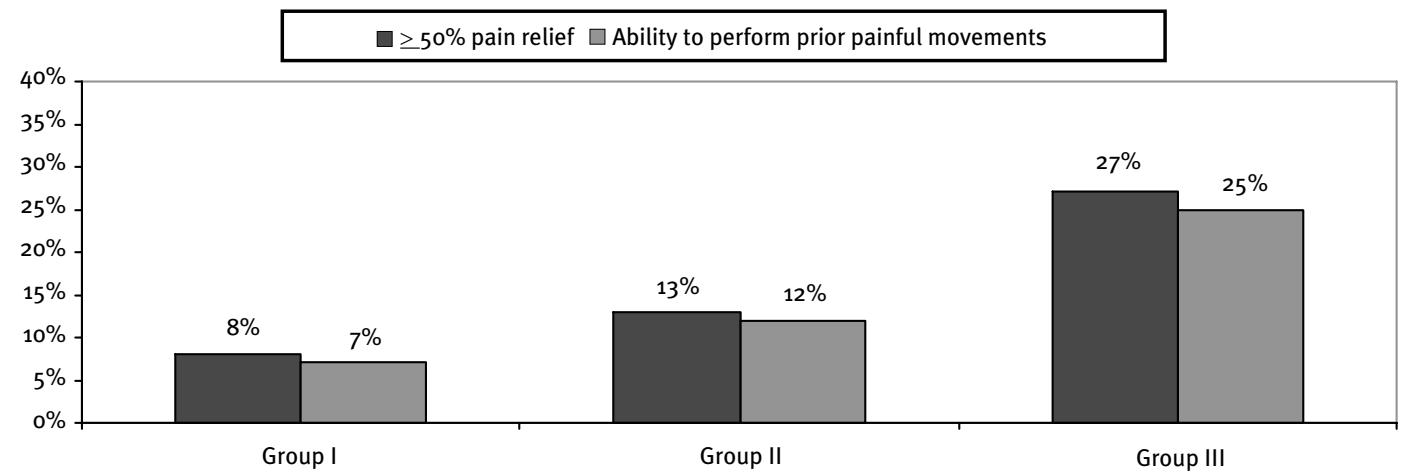

Fig 3. Illustration of $\geq 50 \%$ pain relief and ability to perform baseline painful movements in post-study follow-up period in each group 
Table 5. Ability to perform movements painful prior to injection of solution, following the injection

\begin{tabular}{|c|c|c|c|c|}
\hline & & $\begin{array}{l}\text { Group I } \\
\text { Control }\end{array}$ & $\begin{array}{c}\text { Group II } \\
\text { Midazolam }\end{array}$ & $\begin{array}{l}\text { Group III } \\
\text { Fentanyl }\end{array}$ \\
\hline \multicolumn{2}{|c|}{ Overall ( $\geq \mathbf{5 0} \%$ ) pain relief } & $8 \%(5)$ & $13 \%(8)$ & $27 \% *(16)$ \\
\hline \multicolumn{2}{|c|}{$95 \%$ Confidence Interval } & $1 \%-15 \%$ & $5 \%-22 \%$ & $16 \%-38 \%$ \\
\hline \multirow{2}{*}{$\geq \mathbf{8 0} \%$ Relief } & Yes & $67 \%(2)$ & $100 \%(5)$ & $100 \%(5)$ \\
\hline & No & $33 \%(1)$ & $0 \%$ & $0 \%$ \\
\hline \multirow{3}{*}{$<\mathbf{8 0} \%$ Relief } & Yes & $5 \%(3)$ & $4 \%(2)$ & $18 \%$ * (10) \\
\hline & $95 \%$ Confidence Interval & $0 \%-11 \%$ & $1 \%-9 \%$ & $8 \%-28 \%$ \\
\hline & No & $95 \%(54)$ & $96 \%(53)$ & $82 \%(45)$ \\
\hline \multirow{3}{*}{$\geq 50 \%$ Relief } & Yes & $80 \%(4)$ & $88 \%(7)$ & $94 \%(15)$ \\
\hline & $95 \%$ Confidence Interval & $28 \%-100 \%$ & $47 \%-100 \%$ & $70 \%-100 \%$ \\
\hline & No & $20 \%(1)$ & $12 \%(1)$ & $6 \%(1)$ \\
\hline \multirow{2}{*}{$<50 \%$ Relief } & Yes & $2 \%(1)$ & $0 \%$ & $0 \%$ \\
\hline & No & $98 \%(54)$ & $100 \%(52)$ & $100 \%(44)$ \\
\hline \multirow{2}{*}{$\geq \mathbf{8 0} \%$ Relief } & Relaxed & $100 \%(3)$ & $100 \%(5)$ & $100 \%(5)$ \\
\hline & Not- Relaxed & $0 \%$ & $0 \%$ & $0 \%$ \\
\hline \multirow{3}{*}{$<\mathbf{8 0} \%$ Relief } & Relaxed & $37 \%(21)$ & $87 \% *(48)$ & $95 \% *(52)$ \\
\hline & 95\% Confidence Interval & $24 \%-50 \%$ & $78 \%-90 \%$ & $89 \%-100 \%$ \\
\hline & No-Relaxed & $63 \%(36)$ & $13 \%(7)$ & $5 \%(3)$ \\
\hline \multirow{2}{*}{$\geq \mathbf{5 0} \%$ Relief } & Relaxed & $100 \%(5)$ & $100 \%(8)$ & $100 \%(16)$ \\
\hline & Not- Relaxed & $0 \%$ & $0 \%$ & $0 \%$ \\
\hline \multirow{3}{*}{$<50 \%$ Relief } & Relaxed & $34 \%(19)$ & $87 \% *(45)$ & $93 \% *(41)$ \\
\hline & 95\% Confidence Interval & $22 \%-47 \%$ & $77 \%-96 \%$ & $86 \%-100 \%$ \\
\hline & Not-Relaxed & $66 \%(36)$ & $13 \%(7)$ & $7 \%(3)$ \\
\hline
\end{tabular}

* Indicates significant difference with Group I

\section{Adverse Events}

There were no adverse effects noted in any of the patients studied.

\section{Discussion}

In this randomized, placebo-controlled, double-blind evaluation, we demonstrated that an insignificant proportion of patients had experienced $\geq 80 \%$ pain relief and were able to perform movements painful prior to administration of a solution in patients with chronic neck pain of cervical facet joint origin. However, a greater proportion $(27 \%)$ of patients in Group III reported $\geq 50 \%$ relief and $25 \%$ of the patients in this group were able to perform movements, which were painful prior to injection of a solution. Further, a greater proportion of patients in Group III also showed reduction in the numeric pain scale, and were relaxed. Eight percent of the patients in Group I receiving placebo solution, and $12 \%$ of the patients in Group II were shown to have $\geq 50 \%$ pain relief and were able to perform painful movements of the cervical spine without significant pain follow- ing the administration of drugs. However, there were no significant differences between patients receiving placebo or midazolam, whereas, significant differences were noted between placebo and fentanyl groups. However, there were no significant differences noted between the patients receiving midazolam or fentanyl.

Our observations represent progress in the understanding of confounding factors in the diagnosis of cervical facet joint pain. Based on the results of this study, $5 \%$ of the patients in Group I, 8\% in Groups II and III each presented with $\geq 80 \%$ pain relief, whereas $3 \%$ of the patients in Group I, as well as $8 \%$ of the patients in Groups II and III each were able to perform movements which had been painful prior to injection of medication.

In addition, $8 \%$ of the patients in the control group (95\% CI, 1\% - 15\%), 13\% of the patients in Group II (95\% CI, 5\% $22 \%$ ), and $27 \%$ of the patients in Group III (95\% CI, 15\% - 38\%) experienced $\geq$ $50 \%$ pain relief. Further, $7 \%$ of the patients in Group I (95\% CI, 2\% - 16\%), $12 \%$ in Group II (95\% CI, 6\% - 25\%), and
$25 \%$ of patients in Group III (95\% CI, 6\% - $25 \%$ ) were able to perform movements which were painful prior to administration of the study drugs.

Based on the results of this study, it may be postulated that the diagnosis of facet joint pain in patients with chronic neck pain may provide false-positive results even when they receive a placebo. However, the combination of $80 \%$ relief and the ability to perform prior painful movements was seen only in 3\% of the patients in Group I, and $8 \%$ of the patients in Groups II, and III each. If pain relief and ability to perform prior painful movements are used as the criteria standard to evaluate positive responses to local anesthetic block of a painful facet joint, false-positives appear to be low. Since fentanyl is administered only in patients who are not relaxed and potentially combative, it appears that many patients who receive fentanyl may not be impacted adversely by diluting the value of diagnostic controlled comparative local anesthetic blocks.

False-positives may be a significant factor if $\geq 50 \%$ pain relief and/or the abil- 
ity to perform prior painful movements is used as the criterion standard. Seven percent of the patients in Group I, $12 \%$ in Group II, and 25\% in Group III may present with false-positive results.

Multiple drugs utilized for anxiolysis and analgesia during interventional procedures include benzodiazepines, opioids, and other agents. Midazolam and fentanyl are more frequently used intervenous drugs for intraoperative sedation and analgesia due to the expected short duration of action combined with rapid onset of action. Midazolam is a short-acting benzodiazepine affecting the central nervous system depressant activities. The effects of midazolam on the central nervous system are dependent on the dose administered, the route of administration, and the presence or absence of other medications. Clinical experience has shown midazolam to be 3 to 4 times as potent per mg as diazepam.

Fentanyl is a narcotic analgesic. A dose of $100 \mathrm{mcg}$ or $0.1 \mathrm{mg}$ or $2 \mathrm{~mL}$ is approximately equivalent in analgesic activity to $10 \mathrm{mg}$ of morphine or $75 \mathrm{mg}$ of meperidine. The principle actions of therapeutic value are analgesia and sedation. The onset of action of fentanyl is almost immediate when the drug is given intravenously.

This study confirms that some patients obtaining proper relaxation, either with sodium chloride solution, midazolam, or fentanyl may report significant analgesia of neck pain originating from cervical facet joints. This appears to be in a significant proportion of patients receiving fentanyl, specifically if one considers $\geq 50 \%$ pain relief and ability to perform painful movements as the criterion standard. However, patients who are not relaxed under any type of sedation did not report significant pain relief and also were not able to perform painful movements. Thus, administration of sedation with midazolam to achieve a relaxed status appears to be safe with minimal effect on the diagnostic capacity of diagnostic facet joint nerve blocks. However, the administration of fentanyl in patients without relaxation to achieve a relaxed status may be appropriate from a drug or diagnostic standpoint only with $80 \%$ pain relief as a criterion, but not with $50 \%$ pain relief.

The present evaluation may be criticized for several potential drawbacks. First, there was no additional group with combined midazolam and fentanyl. Second, it may be argued that inclusion criteria were flawed as sedation was given to patients after the diagnosis of facet joint pain was established. Third, it may be argued that we retrospectively inferred the validity of the primary diagnosis. Finally, the study may be criticized for conducting the evaluation in patients previously exposed to the drugs utilized in the study.

The study was placebo-controlled, randomized, double-blind, with $60 \mathrm{pa}$ tients in the smallest group, with appropriate evaluation of outcome parameters of pain relief and ability to perform prior painful movements. The question about an additional group with midazolam and fentanyl may be legitimate. However, administration of the two drugs in a safe manner would have been extremely difficult, specifically limiting the total dosage to $5 \mathrm{~mL}$ with $50 \%$ midazolam and $50 \%$ fentanyl. The drugs cannot be mixed reliably and uniformly. Further, they may have to be provided in two separate syringes. In such a scenario, the study would not be blind. Thus, the combined effect of midazolam with fentanyl was not evaluated. Hence, we do not believe that this was a drawback or a deficiency in the study.

The second issue relates to the inclusion criteria. We employed strict inclusion criteria with patients with history of chronic, functional limiting, neck pain of at least two years of duration, with confirmed evidence of facet joint pain by controlled, comparative local anesthetic blocks and therapeutic medial branch blocks. All the patients included in the study were treated in the past and were presenting for repeat treatment after a significant period of symptom relief.

The third question is related to the inference of the validity of primary diagnosis retrospectively rather than evaluation of effect of sedation. This is also an inaccurate assumption. The effect of sedation was evaluated on the validity of diagnosis and there was nothing retrospective in this study. Thus, the study is best performed in this manner. It may be argued that to answer this question, this study would have needed to actually give the sedation prior to the comparative, controlled local anesthetic blocks performed initially for the purposes of diagnosis. We are uncertain on that issue with regards to the value of such a study as it will not offer any additional information, but also will introduce further confounding factors, as wide variation in the prevalence of cervical facet joint pain has been described in the literature.
Finally, the study was conducted in patients who were previously exposed to the study drugs. We acknowledge that patients do develop tolerance and the response may be attenuated in patients with prior exposure. However, in interventional pain management settings, this situation would be difficult to avoid as most patients have already been exposed to opioids and benzodiazepines prior to presenting for evaluation. Thus, we do not believe that this would alter the results. In addition, this study showed that $57 \%$ of the patients in the placebo group, $72 \%$ of the patients in midazolam group, and $91 \%$ of the patients in fentanyl group received less than $5 \mathrm{~mL}$ to achieve a relaxed status even though they were aware that they could receive additional medication. Thus, even if tolerance has developed, we believe that the response was appropriate at these dose levels.

As described above, this study has its limitations; hence the results of this evaluation should not be generalized. They can only be utilized when the controlled, comparative local anesthetic blocks are performed under strict criteria with $0.5 \mathrm{~mL}$ of anesthetic for each nerve, under fluoroscopic visualization and with application of strict criteria of at least $80 \%$ relief with ability to perform movements which were painful prior to administration of sedation.

\section{Conclusion}

This placebo-controlled, doubleblind evaluation showed that the administration of sedation with midazolam or fentanyl could be a confounding factor in the diagnosis of cervical facet joint pain in patients with chronic neck pain. However, if $\geq 80 \%$ pain relief with the ability to perform prior painful movements is used as the diagnostic standard, the effect of sedation on validity may be extremely low. In contrast, a significant number of patients may present as false-positives if $\geq 50 \%$ pain relief with ability to perform prior painful movements or only ability to perform prior painful movements are used as the diagnostic criteria. Thus, prudent administration of midazolam only to patients who are not relaxed, may not have significant adverse effect on the diagnostic validity of controlled comparative local anesthetic blocks. On the other hand, fentanyl could confound the diagnosis with false-positive results in a significant proportion of patients. 


\section{ACKNOWLEDGEMENTS}

The authors wish to thank Tonie Hotton, and Chandra Sekhar Edam for their assistance in preparation of this manuscript.

The authors also wish to thank editors of Pain Physician for peer review and constructive criticism, which ultimately improved the quality and understanding of the manuscript.

\section{Author Affiliation: \\ Laxmaiah Manchikanti, MD \\ Medical Director \\ Pain Management Center of Paducah \\ 2831 Lone Oak Road \\ Paducah, Kentucky 42003 \\ E-mail: drm@apex.net.}

\section{Vidyasagar Pampati, MSc}

Statistician

Pain Management Center of Paducah 2831 Lone Oak Road

Paducah, Kentucky 42003

E-mail: sagar@thepainmd.com

\section{Kim S. Damron, RN}

Nursing Administrator

Ambulatory Surgery Center

2831 Lone Oak Road

Paducah, Kentucky 42003

E-mail: kim@thepainmd.com

Carla D. McManus, RN, BSN

Assistant Nursing Administrator

Ambulatory Surgery Center

2831 Lone Oak Road

Paducah, Kentucky 42003

E-mail: carla@thepainmd.com

\section{Sheila D. Jackson, RN}

Clinical Coordinator

Ambulatory Surgery Center

2831 Lone Oak Road

Paducah, Kentucky 42003

\section{Renee C. Barnhill, RN}

Clinical Coordinator

Ambulatory Surgery Center

2831 Lone Oak Road

Paducah, Kentucky 42003

E-mail: renee@thepainmd.com

\section{Jennifer C. Martin, RN}

Clinical Coordinator

Ambulatory Surgery Center

2831 Lone Oak Road

Paducah, Kentucky 42003

E-mail: jennifer@thepainmd.com

\section{REFERENCES}

1. Côté DC, Cassidy JD, Carroll L. The Saskatchewan Health and Back Pain Survey. The prevalence of neck pain and related disability in Saskatchewan adults. Spine 1998; 23:1689-1698.

2. Côté DC, Cassidy JD, Carroll L. The factors associated with neck pain and its related disability in the Saskatchewan population. Spine 2000; 25:1109-1117.

3. Bovim G, Schrader H, Sand T. Neck pain in the general population. Spine 1994; 19: 1307-1309.

4. Frederiksson K, Alfredsson L, Koster M et al. Risk factors for neck and upper limb disorders: Results from 24 years of follow up. Occup Environ Med 1999; 56:59-66.

5. Linton SJ, Hellsing AL, Hallden K. A population based study of spinal pain among 35-45-year old individuals. Spine 1998; 23:1457-1463.

6. Hildingsson C, Toolanen G. Outcome after soft-tissue injury of the cervical spine: A prospective study of 93 car accident victims. Acta Orthop Scand 1990; 61:357359.

7. Ylinen J, Ruuska J. Clinical use of neck isometric strength measurement in rehabilitation. Arch Phys Med Rehabil 1994; 75: 465-469.

8. Pennie B, Agambar I. Patterns of injury and recovery in whiplash. Injury 1991; 22: 57-59.

9. Pawl RP. Headache, cervical spondylosis, and anterior cervical fusion. Surg Ann 1977; 9:391-498

10. Bogduk N, Marsland A. The cervical zygapophyseal joints as a source of neck pain. Spine 1988; 13:610-617.

11. Dwyer A, Aprill C, Bogduk N. Cervical zygapophyseal joint pain patterns: A study in normal volunteers. Spine 1990; 6:453457.

12. Aprill C, Dwyer A, Bogduk N. The prevalence of cervical zygapophyseal joint pain patterns II: A clinical evaluation. Spine 1990; 6:458-461.

13. Fukui S, Ohseto K, Shiotani $M$ et al. Referred pain distribution of the cervical zygapophyseal joints and cervical dorsal rami. Pain 1996; 68:79-83.

14. Windsor RE, Nagula D, Storm S et al. Electrical stimulation induced cervical medial branch referral patterns. Pain Physician 2003; 6:411-418.

15. Manchikanti L, Staats P, Singh V et al. Evidence-based practice guidelines for interventional techniques in the management of chronic spinal pain. Pain Physician 2003; 6:3-80.

16. Merskey H, Bogduk N. Classification of Chronic Pain: Descriptions of Chronic Pain Syndromes And Definitions Of Pain Terms. 2nd ed. IASP Press, Seattle, 1994, pp 180181.

17. Barnsley L, Lord SM, Wallis BJ et al. The prevalence of chronic cervical zygapophyseal joint pain after whiplash. Spine 1995;
20:20-26.

18. Lord SM, Barnsley L, Wallis BJ et al. Chronic cervical zygapophysial joint pain with whiplash: A placebo-controlled prevalence study. Spine 1996; 21:1737-1745

19. Manchikanti L, Singh V, Rivera J et al. Prevalence of cervical facet joint pain in chronic neck pain. Pain Physician 2002; 5:243249.

20. Manchikanti L, Singh V, Pampati S et al. Is there correlation of facet joint pain in lumbar and cervical spine? Pain Physician 2002; 5:365-371.

21. Manchikanti L, Boswell MV, Singh V, Pampati V, Damron KS, Beyer CD. Prevalence of facet joint pain in chronic spinal pain of cervical, thoracic, and lumbar regions. BMC Musculoskelet Disord 2004; 5:15.

22. Bogduk N. International Spinal Injection Society guidelines for the performance of spinal injection procedures. Part 1: Zygapophyseal joint blocks. Clin J Pain 1997; 13:285-302.

23. Boswell MV, Singh V, Staats PS et al. Accuracy of precision diagnostic blocks in the diagnosis of chronic spinal pain of facet or zygapophysial joint origin. Pain Physician 2003; 6:449-456.

24. Barnsley L, Bogduk N. Medial branch blocks are specific for the diagnosis of cervical zygapophyseal joint pain. Reg Anesth 1993; 18:343-350.

25. Bogduk N. The clinical anatomy of the cervical dorsal rami. Spine 1982; 7:35-45.

26. Stilwell DL. The nerve supply of the vertebral column and its associated structures in the monkey. Anat Rec 1956; 125:139169.

27. Speldewinde GC, Bashford GM, Davidson IR. Diagnostic cervical zygapophyseal joint blocks for chronic cervical pain. Med J Aust 2001; 174:174-176.

28. Manchikanti L, Manchikanti KN, Damron KS, Pampati V. Effectiveness of cervical medial branch blocks in chronic neck pain: A prospective outcome study. Pain Physician 2004; 7:195-202.

29. Lord SM, Barnsley L, Bogduk N: Percutaneous radiofrequency neurotomy in the treatment of cervical zygapophyseal joint pain: A caution. Neurosurgery 1995; 36: 732-739.

30. Sapir D, Gorup JM. Radiofrequency medial branch neurotomy in litigant and nonlitigant patients with cervical whiplash. Spine 2001; 26:E268-E273.

31. McDonald GJ, Lord SM, Bogduk N. Longterm follow-up of patients treated with cervical radiofrequency neurotomy for chronic neck pain. Neurosurgery 1999; 45:61-68.

32. Barnsley L, Lord S, Wallis B et al. Falsepositive rates of cervical zygapophysial joint blocks. Clin J Pain 1993; 9:124-130.

33. Lord SM, Barnsley L, Bogduk N. The utility of comparative local anesthetic blocks versus placebo-controlled blocks for the diagnosis of cervical zygapophysial joint 
pain. Clin J Pain 1995; 11:208-213.

34. Barnsley L, Lord S, Bogduk N. Comparative local anesthetic blocks in the diagnosis of cervical zygapophysial joints pain. Pain 1993; 55:99-106.

35. Saal JS. General principles of diagnostic testing as related to painful lumbar spine disorders. Spine 2002; 27:2538-2545.

36. Carragee E, Tanner C, Khurana S et al. The rates of false-positive lumbar discography in select patients without low back symptoms. Spine 2000; 25:1373-1381.

37. Carragee EJ, Alamin TF, Miller J et al. Provocative discography in volunteer subjects with mild persistent low back pain. Spine J 2002; 2:25-34.

38. Manchikanti L, Singh V, Pampati V et al. Provocative discography in low back pain patients with or without somatization disorder: A randomized prospective evaluation. Pain Physician 2001; 4: 227-239.

39. Manchikanti L, Pampati V, Fellows B et al. Influence of psychological factors on the ability of diagnose chronic low back pain of facet joint origin. Pain Physician 2001; 4:349-357. 
